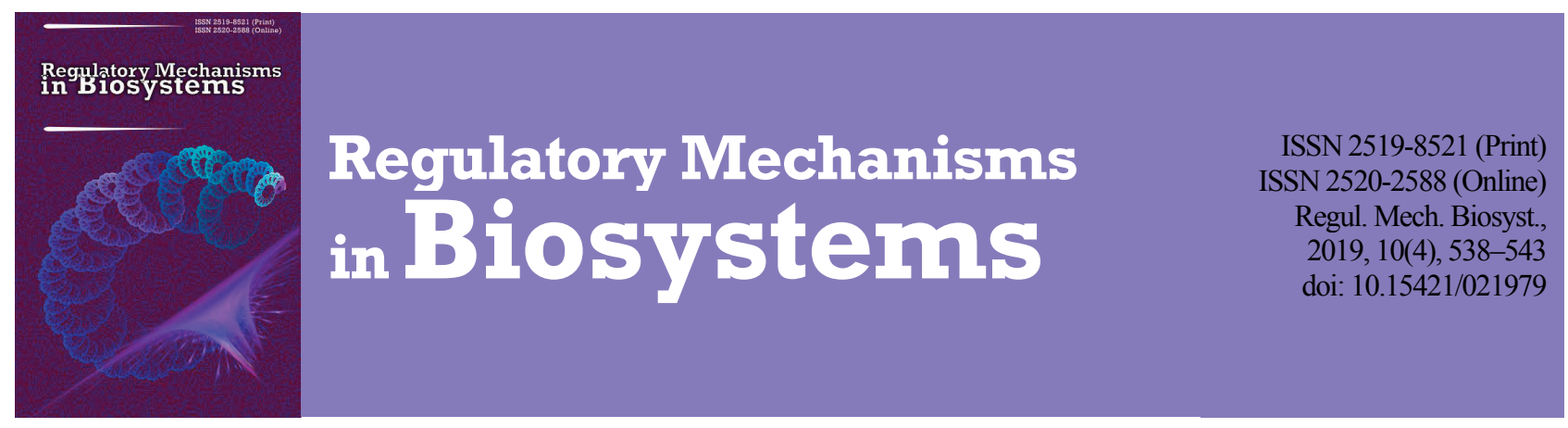

\title{
Functional polarization of macrophages of rats with progesterone-induced obesity treated with melanin from the Antarctic yeast Nadsoniella nigra
}

\author{
V. I. Konopelnuk, I. V. Kompanets, V. M. Svyatetska, O. S. Molozhavaya, L. I. Ostapchenko \\ Taras Shevchenko National University of Kyiv, Kyiv, Ukraine
}

Article info

Received 12.10.2019

Received in revised form 10.11.2019

Accepted 12.11.2019

Taras Shevchenko National University of Kyiv,

Volodymyrska st., 64/13,

Kyiv, 01601, Ukraine

Tel.: +38-098-368-06-79

E-mail:ir_kom@ukr.net

\begin{abstract}
Konopelnuk, V. I., Kompanets, I. V., Svyatetska, V. M., Molozhavaya, O. S., \& Ostapchenko, L. I. (2019). Functional polarization of macrophages of rats with progesterone-induced obesity treated with melanin from the Antarctic yeast Nadsoniella nigra. Regulatory Mechanisms in Biosystems, 10(4), 538-543. doi:10.15421/021979

Progesterone-induced obesity develops in women who use this drug for contraception and the menopause treatment, though its mechanisms remain poorly understood. We studied functional M1 and M2 polarizations of the abdominal cavity macrophages of rats with progesterone induced obesity during 28 days of administration. The effect of melanin from the Antarctic yeast Nadsoniella nigra (Chaetothyriales, Herpotrichiellaceae, Nadsoniella Issatsch, 1914) was investigated. The NO level was determined by the accumulation of nitrites, ROS level was estimated by the NBT-test, arginase activity was assayed by the reaction of L-arginine hydrolysis. The body weights of rats administrated progesterone increased by $27 \%$ and continued to increase one month after withdrawal of progesterone (55\% higher than control). Melanin prevents the weight gain when administered during one month after progesterone withdrawal. The NO production by peritoneal macrophages of obese animals intensified by $31 \%$ indicating their polarization towards pro-inflammatory M1 type. Production of ROS did not change. A 14\% increase in arginase activity was observed, indicating the inhibition of M2 (anti-inflammatory) polarization. In the progesterone withdrawal group all these rates significantly decreased, indicating a reduction in the functional activity of peritoneal macrophages'. Melanin decreased the NO and ROS production by $60 \%$ and $18 \%$ respectively in comparison with the progesterone group and unexpectedly reduced arginase activity. Our data provide evidence of the spread of inflammation in response to progesterone-induced obesity. Peritoneal macrophages are involved in the inflammation in obesity, undergoing polarization towards the pro-inflammatory phenotype. The long-term consequences of such inflammation include the continuation of weight gain and likely the development of systemic inflammation associated with the exhaustion of the functional capacity of peritoneal cavity macrophages. Melanin has an anti-obesity effect and exhibits antiinflammatory properties preventing progesterone-induced weight gain and macrophage M1 polarization. This requires detailed elucidation and can be valuable in designing countermeasures to prevent obesity outcomes.
\end{abstract}

Keywords: progesterone; obesity; melanin; peritoneal macrophages; M1 and M2 polarization.

\section{Introduction}

Obesity is the disease associated with the development of inflamemation not only in adipose tissue but in the whole organism as well. In response to fat accumulation, adipocytes increase their size leading to secretion of proinflammatory cytokines. In obese patients the adipose tissue produces tumour necrosis factor $\alpha$ (TNF- $\alpha$ ), interleukin- $1,-6,-8$, -10 , chemokines MCP-1 and MIP- $\alpha$, C-reactive protein (Kern et al., 2001). This leads to macrophage recruitment to the adipose tissue with subsequent secretion of cytokines and chemokines (Sell \& Eckel, 2010, Harford et al., 2011). The circulation levels of proinflammatory cytokines increase (Curat et al., 2006), reflecting the fact that low-grade inflammation in adipose tissue causes the systemic inflammation in distant organs and tissues (Bullo et al., 2003, Engeli et al., 2003).

The model of progesterone-induced obesity remains incompletely studied. Progesterone is a hormone involved in regulation of reproducetive function. The increase of its production in the luteal phase of menstrual phases leads to an increase in food intake and even binge eating (or emotional eating), which may be accompanied by depression (Klump et al., 2013, Hildebrandt et al., 2015). Progesterone is included in menopausal hormone therapy (MHT) (Coquoz et al., 2018).

Progesterone derivatives used for contraception in adolescent girls (form 12 to 18 years) increase weight gain (Bonny et al., 2006). The treatment of women with progesterone in MHT also increases the food intake, and therefore fat accumulation in the organism (Bonny et al., 2014, Coquoz et al., 2019). Similar effects were observed in rats and mice, which led to the development of the animal model of progesteroneinduced obesity (Kaur \& Kulkarni, 2001, Chidrawar et al., 2011, Gundamaraju et al., 2012, Suneetha et al., 2013). However, only sparse data obtained using such model are available, and these are insufficient for an understanding of progesterone-induced obesity mechanisms.

Macrophages play a pivotal role in the inflammation process in obesity, especially those infiltrating visceral fat tissue (Heilbronn \& Campbell, 2008). They not only secrete inflammatory molecules but also undergo polarization towards M1 type (Sell \& Eckel, 2010). M1 type macrophages produce pro-inflammatory cytokines, nitrogen monoxide and reactive oxygen species (ROS) (Sica \& Mantovani, 2012), thus exacerbating inflammation. Conversely, M2 type macrophages alleviate inflammation, producing anti-inflammatory cytokines and expressing arginase, which is the marker of M2 cells (Rath et al., 2014).

Although the role of visceral fat tissue macrophages in inflammation in obesity is studied the most, more research is needed to clarify the role of peritoneal macrophages. These cells are resident macrophages of the abdominal cavity, involved in the immune response to infection and inflammation by the production of inflammatory mediators, IL-12, MIP-1 $\alpha$, TNF- $\alpha$, and RANTES in particular (Ghosn et al., 2010). The NO production by PLS-stimulated peritoneal macrophages was established, showing their polarization towards M1 type (Sica \& Mantovani, 
2012). The possible development of inflammatory status during obesity would increase our understanding of the mechanism of systemic inflammation development during obesity.

Chronic oxidative stress in fat tissue is one of the obesity outcomes which develop due to low oxygen delivery (Wood et al., 2009). Due to hypertrophy of adipocytes and leucocyte adhesion to the blood vessels walls, the blood supply becomes reduced, leading to hypoxia with subsequent inflammatory status induction (Trayhurn et al., 2008). Earlier studies have demonstrated that visceral fat accumulation leads to not only local but also to systemic oxidative stress (Furukawa et al., 2004). The increased levels of ROS and decreased expression of antioxidant enzymes were observed in fat tissue, and soon after that, in blood plasma (Vincent et al., 2005). Systemic oxidative stress in obesity exacerbates due to the depletion of antioxidants (Fernández-Sánchez et al., 2011).

Therefore, antioxidants attract particular attention in the search for treatment of obesity (Pandey \& Rizvi 2009). There has been much interest in the benefits of dietary plant polyphenols due to their antioxidant properties. Green tea catechins, resveratrol from grape and red vine and some berries, and curcumin from spices suppress obesity in humans and animals by inhibiting the lipolysis, adipocyte proliferation and inflammation (Bogdanski et al., 2012, Tian et al., 2013).

Melanin from Antarctic black yeast Nadsoniella nigra (Herpotrichiellaceae, Nadsoniella Issatsch, 1914) is a promising instrument to improve inflammatory conditions in obesity. This substance is the analogue of human skin melanin and is considered to be a potent antioxidant.

Previously, melanin was observed to exhibit anti-inflammatory, antiulcer (Golyshkin et al., 2015), antistress (Falalyeyeva et al., 2009) and antitumour properties (Permyakova et al., 2016). Yeast melanin prevents visceral fat accumulation in animals with glutamate-induced nonalcoholic liver disease, decreases the blood level of proinflammatory cytokine IL-1 $\beta$ and increases the level of anti-inflammatory cytokines IL-10, TGF-b (Belemets et al., 2017). Because obesity is associated with systemic oxidative stress, melanin may have the potential to prevent or ameliorate obesity-related pathologies.

The objective of this study was clarification of the relationship between body mass changes and the markers of functional polarization of peritoneal macrophages in rats with progesterone-induced obesity and study of the effect of melanin from Antarctic black yeast $N$. nigra against these symptoms.

\section{Materials and methods}

All manipulations were compliant with the Guide for the Care and Use of Laboratory Animals of the National Institutes of Health, Convention on Bioethics of Council of Europe (1997), First National Congress of Ukraine on Bioethics (September 2001). The present study used female rats (2-month-old, weight about $210 \pm 20 \mathrm{~g}$ ). The animals were housed in standard conditions of vivarium in the EducationalScientific Complex of the Institute of Biology and Medicine.

All animals were randomly divided into 4 groups. Each experimental group consisted of 10 animals, housed in collective cages ( 5 per cage) in controlled temperature $\left(22 \pm 1{ }^{\circ} \mathrm{C}\right)$, humidity $(60-65 \%)$, and $12 \mathrm{~h}$ light dark cycle, with food and water accessible ad libitum. The first group (Control) was injected with arachis oil, used as diluents for progesterone. Animals of the second group $(\mathrm{Control}+\mathrm{Mel})$ were treated per os with melanin solution in the dose of $5 \mathrm{mg} / \mathrm{kg}$. Melanin isolated from Antarctic black yeast $N$. nigra was provided by the Ukrainian Antarctic Station. The third group $(\mathrm{Pg})$ received intramuscular injections of progesterone solution (Biopharma, Kyiv, Ukraine) in arachis oil daily for 28 days in the dose of $10 \mathrm{mg} / \mathrm{kg}$. The progesterone dose was used as recommended by (Reddy \& Kulkarni (1998), who demonstrated the most apparent hyperphagic effect of this progesterone dose. It has also been demonstrated that such a dose is used to develop the model of progesterone-induced obesity in mice (Gundamaraju et al., 2012; Suneetha et al., 2013). The fourth group (Pg withdrawal) was treated with progesterone, as outlined above, and then the animals were kept for one month without any treatment. Animals of the fifth group $(\mathrm{Pg}+\mathrm{Mel})$ were treated with progesterone for 28 days, and after that with melanin, as outlined above. The animals were euthanized using carbon dioxide.
The isolation of peritoneal macrophages. After euthanasia, $10 \mathrm{~mL}$ of cold physiological solution was injected intraperitoneally and massaged. The abdominal fluid was aspirated by a syringe and then collected into sterile tubes that were centrifuged at $1,500 \mathrm{rpm}$ for $10 \mathrm{~min}$. The precipitate (cell suspension) was resuspended in $1 \mathrm{~mL}$ of RPMI medium which contained $10 \%$ FCS and $40 \mu \mathrm{g} / \mathrm{mL}$ gentamycin. Cell viability was determined using hemocytometer in $0.4 \%$ trypan blue exclusion technique (Skivka et al., 2013). Peritoneal macrophages were resuspended in the medium, as outlined above, and diluted to concentration $5 \times 10^{6} \mathrm{cells} / \mathrm{mL}$. The level of oxygen species was measured in isolated macrophages by NBT-test (nitro blue tetrazolium test) immediately. To determine the arginase activity and $\mathrm{NO}$ production macrophages were cultured for 18 hours at $37^{\circ} \mathrm{C}$.

NO production assay. The NO production by peritoneal macrophages was determined by the accumulation of stable degradation products nitrites (Skivka et al., 2013). Cells were inoculated $\left(2 \times 10^{5} \mathrm{cells} / \mathrm{mL}\right)$ in quadruplicates in wells of a polystyrene flat-bottomed 96-well microplate and cultured in RPMI 1640 medium with addition of $10 \%$ fetal bovine serum and $1 \%$ gentamicin during 18 hours at $37{ }^{\circ} \mathrm{C}$ and $5 \% \mathrm{CO}_{2}$. The supernatant (cell medium) was collected and used for the determination of nitrites using Griess reagent $(0.2 \% \mathrm{~N}-1$-naphthyl ethylenediamine dihydrochloride mixed with an equal volume of $2 \%$ sulfanilamide dissolved in $10 \%$ phosphoric acid). $100 \mu \mathrm{L}$ of Griess reagent was added to an equivalent volume of cell medium and incubated in quadruplicate in 96-well plate in room temperature for $30 \mathrm{~min}$ in the dark. The absorbance was read at $550 \mathrm{~nm}$ using an automated plate reader (Bio-Rad, USA). The nitrite level in the medium was calculated from a sodium nitrite $\left(\mathrm{NaNO}_{2}\right)$ standard curve and expressed as mmoles per $10^{6}$ cells.

NBT assay. Peritoneal macrophages were washed in Hanks' soluteon by centrifugation at $1,500 \mathrm{rpm}$ for $10 \mathrm{~min}$ and then resuspended in the same solution to the concentration of $1 \times 10^{6}$ cells $/ \mathrm{mL}$. The suspension of $100 \mathrm{~mL}$ of washed cells were inoculated to the wells of a polystyrene flat-bottomed 96-well microplate (Nest Biotech Co., Ltd, China) and incubated at $37^{\circ} \mathrm{C}$ for $30 \mathrm{~min}$ to allow cells to adhere to the plate.

The ROS production by peritoneal macrophages was estimated by NBT assay (Skivka et al., 2013). Then $100 \mu \mathrm{L}$ of $0.1 \%$ nitro-blue tetrazolium chloride (NBT) (Sigma-Aldrich, USA) was added per well and incubated with $0.1 \%$ nitro blue tetrazolium (NBT) (Sigma-Aldrich, USA) at $37^{\circ} \mathrm{C}$ forg $15 \mathrm{~min}$. To trigger the oxidative burst, zymosan A (from Saccharomyces cerevisiae, Sigma-Aldrich, USA) was added to the final concentration of $600 \mu \mathrm{g} / \mathrm{mL}$.

The supernatant was removed from the wells and the reaction was stopped by adding the $100 \mu \mathrm{L}$ of $2 \mathrm{M} \mathrm{KOH}$. Insoluble formazan product was dissolved in $100 \mu \mathrm{L}$ of $50 \%$ dimethyl sulphoxide (DMSO) (Sigma-Aldrich, USA). The absorbance was read at $630 \mathrm{~nm}$ by a plate reader (Bio-Rad, USA).

Arginase activity assay. Peritoneal macrophages were inoculated into wells of a flat-bottom microtiter plate (Nest Biotech Co., Ltd, China) at $2 \times 10^{5}$ per well. Cells were cultured in RPMI 1640 supplemented with $10 \%$ Bovine fetal serum and $1 \%$ gentamicin and $5 \% \mathrm{CO}_{2}$. at $37{ }^{\circ} \mathrm{C}$ for $18 \mathrm{~h}$. The next day nonadherent cells were separated from adherent cells by washing in $200 \mu \mathrm{L}$ of Phosphate Buffer Solution (PBS). The cells were lysed by the addition of $100 \mu \mathrm{L}$ of $0.1 \%$ Triton X-100.

Amount of $100 \mu \mathrm{L}$ of $50 \mathrm{mM}$ Tris-HCl, $\mathrm{pH} 7.4,1.0 \mu \mathrm{M} \mathrm{MnCl}_{2}$, was added to the suspension, all procedures were undertaken at $4{ }^{\circ} \mathrm{C}$. Arginase activity in macrophages was activated by heating the mixture at $56{ }^{\circ} \mathrm{C}$ for $7 \mathrm{~min}$. The reaction of L-arginine hydrolysis was initiated by the addition of $100 \mu \mathrm{L}$ of arginine $(0.5 \mathrm{M}, \mathrm{pH} 9.7)$. After that the mixture was incubated at $37^{\circ} \mathrm{C}$ for 3 hours. The urea solutions of the following concentrations were used as standards: 7.5, 15, 30, 45, $60 \mu \mathrm{g}$ per $100 \mu \mathrm{L}$ of $\mathrm{H}_{2} \mathrm{O}$. The reaction was stopped by the addition of $800 \mu \mathrm{L}$ of an acid mixture $\left(\mathrm{H}_{3} \mathrm{PO}_{4}: \mathrm{H}_{2} \mathrm{SO}_{4}: \mathrm{H}_{2} \mathrm{O}=1: 3: 7\right)$. The amounts of $900 \mu \mathrm{L}$ of the same solution were added to the standards.

For colorimetric determination of urea, $40 \mu \mathrm{L}$ of $6 \% \alpha$-ionitrosopropiophenone ( $\alpha$-ISPP) (Sigma-Aldrich, USA) dissolved in $9 \%$ ethanol was added to all wells, including the standards (Skivka et al., 2013). Mixtures were incubated at $95{ }^{\circ} \mathrm{C}$ for $30 \mathrm{~min}$ and then at $4{ }^{\circ} \mathrm{C}$ for $30 \mathrm{~min}$. The absorbance was measured at $\lambda=540 \mathrm{~nm}$ using an automated plate reader (Bio-Rad, USA). Arginase activity was calculated 
using a standard calibration curve developed according to the standard concentrations of $\mu \mathrm{g}$ urea.

The data were expressed as units of arginase per $1 \times 10^{6}$ cells: the amount of $\mu \mathrm{g}$ urea $(\mu \mathrm{g})$ divided by 60 (molecular weight of urea) was multiplied by 50 (dilution factor) divided by the time (minutes) of incubation with arginine. One unit of arginase activity means the amount of enzyme needed to hydrolyze $1 \mu \mathrm{M}$ arginine per minute.

Results are expressed as the average of the eight measures (x) and standard deviation (SD). Statistical analysis was performed using the Shapiro-Wilk test, the groups were compared using one-way ANOVA by homogenity variance test (Levene's test), followed by significant difference test (Bonferroni test). A P-value less than 0.05 was considered statistically significant.

\section{Results}

Body weights. To confirm the obesity development in animals in the first stage we determined body weights in all groups. The increase of body weight by $27 \%$ was observed in rats treated with progesterone for 28 days (Fig. 1). In the Pg withdrawal group of animals that had not been treated for a month, bodyweight did not return to its initial value and even did not decrease significantly: it exceeded the control level by $34 \%$ (Fig. 1). In animals that were treated with melanin for 28 days after 28-day progesterone treatment ( $\mathrm{Pg}+\mathrm{Mel}$ group), the body weight was $12 \%$ lower in comparison with the Pg group. Thus, melanin prevented further weight gain in animals with progesterone-induced obesity: in this case, it exceeded the control only by $9 \%$. Notably, melanin did not affect the body weight in healthy animals (Mel group).

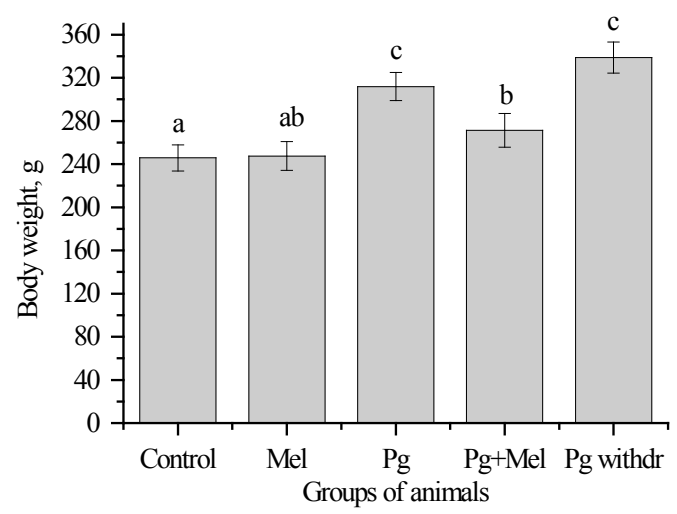

Fig. 1. Body weight of rats injected with progesterone $(10 \mathrm{mg} / \mathrm{kg})$ for 28-days and after that treated with melanin $(5 \mathrm{mg} / \mathrm{kg})$ for

28-days ( $\mathrm{x} \pm \mathrm{SD}, \mathrm{n}=10)$ : Mel Melanin group, $\mathrm{Pg}$ - Progesterone group, $\mathrm{Pg}+\mathrm{Me}-$ Progesterone+Melanin group, $\mathrm{Pg}$ withdr -

Progesterone withdrawal group; different letters indicate values which reliably differed one from another according to the results of comparison using Tukey's test with Bonferroni correction

NO production. The NO level in animals administrated with progesterone (Pg group) increased by $31 \%$ in comparison with the control group (Fig. 2). We have demonstrated that in the Pg withdrawal group (in the month after progesterone withdrawal) the NO level declined by $64 \%$ compared with the Pg group, being 53\% lower than control. The study revealed that melanin effect reduced NO level by $60 \%$ in macrophages in rats treated with progesterone ( $\mathrm{Pg}+\mathrm{Mel}$ group), compared with the Pg group. We should note that NO level declination was less significant in healthy animals (Control+Mel group): it was $42 \%$ lower than in the Control group.

ROS level. The change of ROS production was not statistically reliable in the progesterone-treated rats in comparison to the healthy ones (Control group) (Fig. 3). Surprisingly, in the Pg withdrawal group the ROS level decreased $29 \%$ compared with control. At the same time, melanin introduced to animals 1 month after progesterone withdrawal (PG withdrawal group) decreased the ROS level by $18 \%$ compared with the Pg group. A similar trend was observed in the Control+Mel group: melanin administration to control animals decreased the ROS level by $10 \%$ in comparison with the Control group.

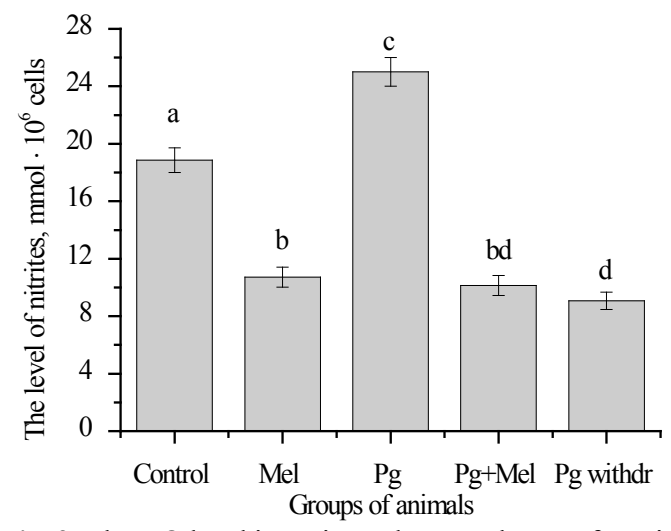

Fig. 2. The NO level in peritoneal macrophages of rats injected with progesterone $(10 \mathrm{mg} / \mathrm{kg})$ for 28 -days and after that treated with melanin $(5 \mathrm{mg} / \mathrm{kg})$ for 28 -days $(\mathrm{x} \pm \mathrm{SD}, \mathrm{n}=10)$ : see Fig. 1

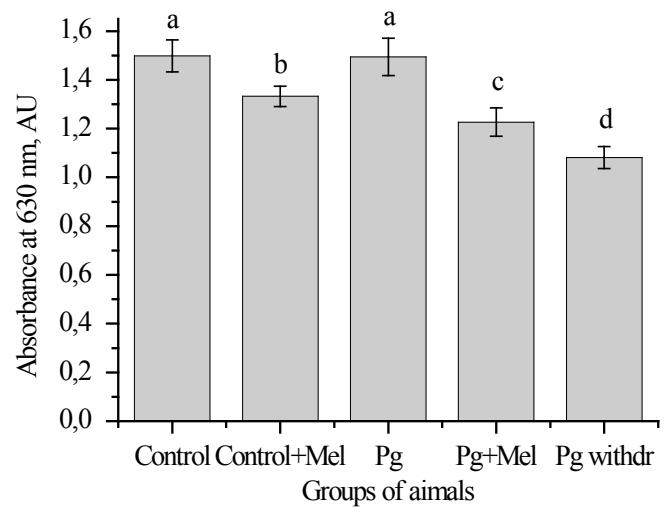

Fig. 3. The level of oxygen-dependent metabolism in peritoneal macrophages of rats injected with progesterone $(10 \mathrm{mg} / \mathrm{kg})$ for 28-days and after that treated with melanin $(2 \mathrm{~mL} / \mathrm{kg})$ for 28-days, $\mathrm{n}=8$, see Fig. 1

Arginase activity. The arginase activity was observed to decrease by $14 \%$ in rats treated with progesterone (Pg group), compared to control (Fig. 4). It means that the M2 polarization of macrophages is suppressed in this model of obesity. This data correlates with the data on increase of macrophages M1 polarization which is reflected in increase in NO production. However, in the Pg withdrawal group enzyme activity fell significantly and became lower than the control by $55 \%$.

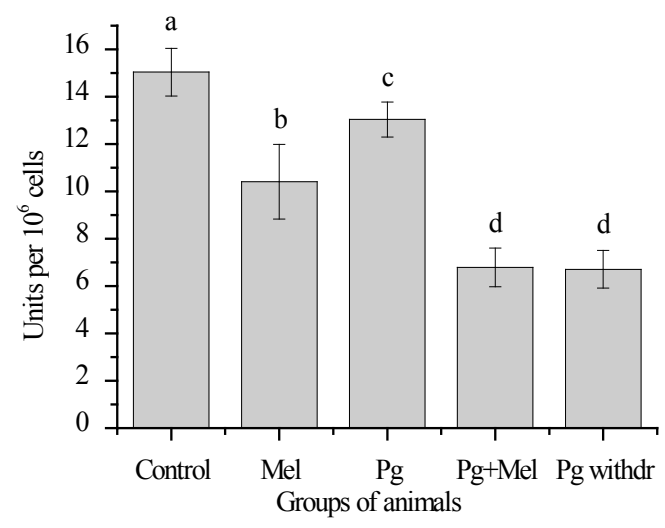

Fig. 4. The arginase activity in peritoneal macrophages of rats injected with progesterone $(10 \mathrm{mg} / \mathrm{kg})$ for 28 -days and after that treated with melanin $(5 \mathrm{mg} / \mathrm{kg})$ for 28 -days $(\mathrm{x} \pm \mathrm{SD}, \mathrm{n}=10)$ : see Fig. 1

Unexpectedly, in animals treated with melanin after progesterone (Pg + Mel group) the arginase activity reduced by $48 \%$ in comparison to animals treated with progesterone only. At the same time, in healthy 
animals melanin decreased the enzyme activity in a less pronounced way and was $31 \%$ lower than the control.

\section{Discussion}

Our present study demonstrated on the animal model that in progesterone-induced obesity the inflammatory process developed in the abdominal cavity. We induced the obesity model by progesterone introduction to animals over 28 days. These data indicate that progesterone treatment causes obesity, which complements the data from mouse models of progesterone-induced obesity (Kaur \& Kulkarni, 2001).

The weight gain in response to progesterone may be caused by an increase in food intake by animals (non-published results). Progesterone is a neuroactive steroid that, as was mentioned above, is produced in women during the menstrual phase and can cause a hyperphagic effect (Klump et al., 2013). The mechanism of progesterone-induced obesity differs from those for high-fat diet and is associated with the increase in food intake (emotional eating) (Klump et al., 2013).

Since, after progesterone withdrawal, the growth of body mass does not stop, but, on contrary, increases, we can assume that pathological processes which lead to obesity do not stop and aggravate the inflamemation in the organism leading to disorders in metabolic pathways. In particular, changes in lipid metabolism may develop, leading to an increase of fat accumulation in adipocytes. This is consistent with the data about the stimulation of adipocyte growth in response to progesterone by indirectly enhancing the expression of the fatty acid synthase (Eberlé et al., 2004).

Since Antarctic yeast melanin prevents progesterone-induced weight gain, it may have a beneficial effect when used for obesity prophylaxis. Probably, it causes such effect due to its antioxidant and anti-inflammatory properties as demonstrated in a number of studies (Falalyeyeva et al., 2009; Permyakova et al., 2016; Belemets et al., 2017).

Studies in other obesity models have shown that local inflammation in adipose tissue causes systemic inflammation (Weisberg et al., 2003; Heilbronn \& Campbell, 2008). The studies also revealed that not only fat tissue macrophages are implicated in inflammation in obesity; resident macrophages of other tissues are also involved in these events (Shaw et al., 2014). The mechanism of progesterone-induced obesity remains incompletely understood. It may be assumed that similarly to other types of obesity the fat accumulation in adipose tissue causes local inflammation which can further cause systemic inflammation. Therefore to identify the inflammatory process in the organism, one should first assess the contributions of abdominal cavity macrophages which respond to changes in the fat tissue first.

Taking into account the data about inflammation obtained from other animal models of obesity (Sell \& Eckel, 2010; Harford et al., 2011) and our results, we assume that in progesterone-induced obesity inflammation will possibly develop in the abdominal cavity. To confirm this assumption we evaluated the main markers of peritoneal macrophages polarization: pro-inflammatory M1 markers (NO production and ROS level) and antiinflammatory M2 markers (arginase activity).

The study revealed an increase of NO level that could be an indication of polarization of macrophages towards pro-inflammatory M1 type, likely caused by inflammation in the adipose tissue. Our data coincide with the results which demonstrate that $\mathrm{NO}$ production intensifies in the fat tissue of humans (Hrabák et al., 2011) and animals (Gil-Ortega et al., 2010) with diet-induced obesity. Moreover, the increase of NO production was found not only in the fat tissue but also in leucocytes of children with inflammation associated with obesity (Hrabák et al., 2011).

At the next stage, we tested the arginase activity which is an important anti-inflammatory polarization marker. This enzyme is expressed together with pro-inflammatory cytokines in M2 macrophages (Rath et al., 2014) and is involved in the development of inflammation in response to viral infection and tumour growth (Narita et al., 2013; Takele et al., 2013).

The decrease of arginase activity in animals with progesteroneinduced obesity is possibly associated with the decrease in peritoneal macrophages' ability to polarize towards M2 anti-inflammatory type. Also, it is possible, that these cells can take no part in the immune response in obesity. This fact is indicated by the data obtained on the the mouse model, in which the obesity M2 macrophages were not involved in the inflammatory status formation; in contrast, their number increased in lean mice (Lumeng et al., 2007).

Thus, the increase of NO production together with the decrease of arginase activity indicates the stimulation of their polarization towards proinflammatory phenotype and the suppression of polarization towards antiinflammatory one respectively. Our findings suggest the development of inflammation in the abdominal cavity in progesterone-induced obesity. Our suggestion is supported by the notion that excessive accumulation of visceral fat in abdominal obesity causes local inflammation in fat tissue followed by systemic inflammation (Bullo et al., 2003, Engeli et al., 2003). Therefore, the induction of inflammatory status in peritoneal macrophages in progesterone-induced obesity could be the outcome of inflammation in the abdominal cavity due to fat accumulation.

Also, in a model of progesterone-induced obesity we have revealed the link between the increases of animals' body weight and the augmentation of polarization of abdominal cavity macrophages towards pro-inflammatory phenotype. A similar correlation between body mass, some metabolic parameters, and markers of inflammation has been demonstrated in obese patients with polycystic ovary syndrome (Durmus et al., 2017).

Our data regarding the implication of peritoneal macrophages in inflammation development in the organism are consistent with findings from other obesity models. The induction of inflammatory status in peritoneal macrophages in mice with high-fat-diet-induced obesity (Wu et al., 2013) and also the augmentation of M1 polarization along with the suppression of M2 polarization (Zhang et al., 2016) have been reported.

Oxidative stress is believed to be the integral part of inflammation in obesity not only in fat tissue (Trayhurn et al., 2008; Wood et al., 2009), but also in whole organism (Furukawa et al., 2004) with attendant production of reactive oxygen and nitrogen species (Nathan, 2008). Several reports suggest ROS accumulation not only in fat tissue but also in the serum of people and animals with obesity (Fernández-Sánchez et al., 2011; Marseglia et al., 2014). In this context, we have estimated by NBT assay the ROS level in peritoneal macrophages of rats with progesterone-induced obesity. In spite of evidence of the occurrence of oxidative stress in fat tissue in obesity (Furukawa et al., 2004), we have not revealed the oxygen-dependent metabolism stimulation in macrophages of progesteronetreated rats. We surmise that with progesterone-induced obesity the augmentation of macrophages polarization towards the M1 pro-inflammatory phenotype is implemented through the NO production in contrast to ROS production. We suggest that these effects could reflect the immune response to inflammation in fat tissue.

Notably, the long-term consequences (Pg withdrawal group) include the decrease of all markers of M1 and M2 polarization: both NO and ROS level as well as arginase activity respectively. All markers became lower not only comparative to the progesterone group but also relative to healthy animals. It likely mirrors the suppression of functional capacity of peritoneal macrophages that is not restored and but rather aggravated in the inflammatory process upon obesity development. This suggestion is in agreement with the fact that in the progesterone withdrawal group the bodyweight continues to rise after the progesterone withdrawal.

Our findings suggest that with progesterone-induced obesity the polarization of the macrophages towards pro-inflammatory type increased, while the polarization towards anti-inflammatory type is suppressed. Our data are consistent with the results indicating that inflammatory response in obesity is accompanied by an increase of $\mathrm{M} 1$ polarization and alleviation of M2 polarization of both macrophages in adipose tissue (Lumeng et al., 2007; Fujisaka et al., 2009) and peritoneal macrophages (Zhang et al., 2016). The revealed changes of these cells functioning could be interpreted as the response to the violation of the peritoneal cavity microenvironment, the production of inflammatory molecules (cytokines), produced in adipose tissue, in particular. This agrees with the evidence that systemic inflammation in obesity is the outcome of local inflammation accompanied by the decrease in the number of M2 macrophages in adipose tissue (Heilbronn \& Campbell, 2008). Perhaps, 1 month after progesterone withdrawal, the consequences of the inflammatory process in fat tissue are not mitigated, resulting in the depletion of the functional ability of macrophages. The present study also aimed to examine the effect of Antarctic yeast melanin on the above-noted markers of macrophages po- 
larization. Melanin has attracted particular attention due to its antioxidant and anti-inflammatory properties. We have demonstrated that melanin not only prevents weight gain but also suppresses the polarization of peritoneal macrophages. It causes a decrease in $\mathrm{M} 1$ polarization markers $\mathrm{NO}$ and ROS production) in obese animals. Notably, the effect of melanin in healthy animals was similar but less pronounced.

Arguably, melanin reduces the inflammation in the abdomen caused by body weight increase. This effect could be associated with melanin antioxidant properties, meaning its ability to scavenge hydroxyl radicals and superoxide anions.

We suppose that in cases of obesity melanin prevents activation of abdominal cavity macrophages in response to low-grade inflammation in fat tissue and it, therefore, could have anti-inflammatory properties. This is consistent with previous studies, where melanin was shown to reduce the level of pro-inflammatory cytokine IL-1 $\beta$ and restore the level of antiinflammatory cytokines (IL-10, TGF-b) in the serum of rats with non-alcoholic liver disease induced by monosodium glutamate (Belemets, 2017). As noted previously, the antioxidant properties of melanin are linked to its anti-inflammatory, antitumour and gastroprotective effects, as demonstrated in several articles (Falalyeyeva et al., 2009; Golyshkin et al., 2015; Permyakova et al., 2016; Belemets et al., 2017). Taking into account that melanin doesn't elevate but reduces arginase activity, which was decreased in obese animals, it can be assumed that it cannot stimulate the ability of macrophages to polarize towards the pro-inflammatory phenotype that was suppressed in obesity. Probably, it causes an anti-inflammatory effect via the suppression of NO production. This effect requires further examination. Our assumption is consistent with the reported studies, that is, endogenous melanin level increases in adipose tissue of obese patients (Page et al., 2011). It is suggested that this pigment has antioxidant and anti-inflammatory properties: it can scavenge free radicals, thus reducing the oxidative stress and alleviating inflammation.

Taken together, the data from the present study have shown that the beneficial effect of melanin on hormonal obesity is implemented through the suppression of inflammatory processes in an organism, in particular by the prevention of macrophages' activation. On this basis, melanin may have the potential to improve inflammatory and metabolic conditions in obesity which develops due to progesterone use in menopausal therapy or contraception.

\section{Conlusion}

The results of the present study suggest that the 28-day treatment of rats with progesterone causes obesity, as evidenced by the $27 \%$ increase in body weights. This is accompanied by the polarization of peritoneal macrophages towards the M1 pro-inflammatory phenotype: the production of $\mathrm{NO}$ is increased in contrast to ROS generation, which doesn't change. $\mathrm{M} 2$ polarization of macrophages towards the M2 anti-inflammatory phenotype is suppressed: arginase activity decreases. Thus, progesterone-induced weight gain due to visceral fat accumulation causes inflammatory status formation that affects peritoneal cavity macrophages.

One month after progesterone withdrawal, weight gain remains increased, and the consequences of the inflammatory process are aggravated leading to depletion of functional capacity of macrophages. Their ability to polarize is suppressed, as reflected in the decrease of the studied M1 and M2 markers: NO and ROS production and arginase activity, respectively. It can be assumed that the inflammatory process caused by obesity starts moving from fat tissue to other tissues and organs and those changes are irreversible. The findings are aligned with the data from other obesity models regarding the development of a systemic inflammatory process in response to local inflammation in fat tissue.

Melanin from Antarctic black yeast $N$. nigra prevents the aggravation of progesterone-induced obesity in rats, impeding the weight gain and exhibits anti-inflammatory properties via lowering of NO and ROS production. Further studies are needed to establish the possibility of using melanin to mitigate the consequences of obesity.

\section{References}

Belemets, N., Kobyliak, N., Virchenko, O., Falalyeyeva, T., Olena, T., Bodnar, P., Savchuk, O., Galenova, T., Caprnda, M., Rodrigo, L., Skladany, L., Delev,
D., Opatrilova, R., Kruzliak, P., Beregova, T., \& Ostapchenko, L. (2017). Effects of polyphenol compounds melanin on NAFLD/NASH prevention. Biomedicine and Pharmacotherapy, 88, 267-276.

Bogdanski, P., Suliburska, J., Szulinska, M., Stepien, M., Pupek-Musialik, D., \& Jablec$\mathrm{ka}, \mathrm{A}$. (2012). Green tea extract reduces blood pressure, inflammatory biomarkers, and oxidative stress and improves parameters associated with insulin resistance in obese, hypertensive patients. Nutrition Research, 32, 421-427.

Bonny, A. E., Lange, H. L. H., Rogers, L. K., Gothard, D. M., \& Reed, M. D. (2014). A pilot study of depot medroxyprogesterone acetate pharmacokinetics and weight gain in adolescent females. Contraception, 89(5), 357-360.

Bonny, A. E., Ziegler, J., Harvey, R., Debanne, S. M., Secic, M., \& Cromer, B. A. (2006). Weight gain in obese and nonobese adolescent girls initiating depot medroxyprogesterone, oral contraceptive pills, or no hormonal contraceptive method. Archives of Pediatrics and Adolescent Medicine, 160(1), 40-45.

Bullo, M., Garcia-Lorda, P., Megias, I., \& Salas-Salvado, J. (2003). Systemic inflammation, adipose tissue tumor necrosis factor, and leptin expression. Obesity Research, 11(4), 525-531.

Chidrawar, V. R., Patel, K. N., Sheth, N. R., Shiromwar, S. S., \& Trivedi, P. (2011). Antiobesity effect of Stellaria media against drug induced obesity in Swiss albino mice. Ayu, 32(4), 576-584.

Coquoz, A., Gruetter, C., \& Stute, P. (2019). Impact of micronized progesterone on body weight, body mass index, and glucose metabolism: A systematic review. Climacteric, 22(2), 148-161.

Curat, C. A., Miranville, A., Sengenès, C., Diehl, M., Tonus, C., Busse, R., \& Bouloumié, A. (2004). From blood monocytes to adipose tissue-resident macrophages: Induction of diapedesis by human mature adipocytes. Diabetes, 53(5), 1285-1292.

Durmus, U., Duran, C., \& Ecirli, S. (2017). Visceral adiposity index levels in overweight and/or obese, and non-obese patients with polycystic ovary syndrome and its relationship with metabolic and inflammatory parameters. Journal of Endocrinological Investigation, 40(5), 487-497.

Eberlé, D., Hegarty, B., Bossard, P., Ferré, P., \& Foufelle, F. (2004). SREBP transcription factors: Master regulators of lipid homeostasis. Biochimie, 86(11), 839-848.

Engeli, S., Feldpausch, M., Gorzelniak, K., Hartwig, F., Heintze, U., Janke, J., Möhlig, M., Pfeiffer, A. F., Luft, F. C., \& Sharma, A. M. (2003). Association between adiponectin and mediators of inflammation in obese women. Diabetes, 52, 942-947.

Falalyeyeva, T. M., Tsyryuk, O. I., Chyizhanska, N. V., \& Zharova, V. P., (2009). The influence of melanin isolated from Antarctic yeasts on cortisol blood level of rats in conditions of stress action. Ukrainian Antarctic Joumal, 8, 391-394.

Fernández-Sánchez, A., Madrigal-Santillán, E., Bautista, M., Esquivel-Soto, J., Morales-González, A., Esquivel-Chirino, C., Durante-Montiel, I., Sánchez-Rivera, G., Valadez-Vega, C., \& Morales-González, J. A. (2011), Inflammation, oxidative stress, and obesity. International Journal of Molecular Sciences, 12(5), 3117-3132.

Fujisaka, S., Usui, I., Bukhari, A., Ikutani, M., Oya, T., Kanatani, Y., Tsuneyama, K., Nagai, Y., Takatsu, K., Urakaze, M., Kobayashi, M., \& Tobe, K. (2009). Regulatory mechanisms for adipose tissue M1 and M2 macrophages in dietinduced obese mice. Diabetes, 58(11), 2574-2582.

Furukawa, S., Fujita, T., Shimabukuro, M., Iwaki, M., Yamada, Y., Nakajima, Y., Nakayama, O., Makishima, M., Matsuda, M., \& Shimomura, I. (2004). Increased oxidative stress in obesity and its impact on metabolic syndrome. Journal of Clinical Investigation, 114(12), 1752-1761.

Ghosn, E. E., Cassado, A. A., Govoni, G. R., Fukuhara, T., Yang, Y., Monack, D. M., Bortoluci, K. R., Almeida, S. R., Herzenberg, L. A., \& Herzenberg, L. A. (2010). Two physically, functionally, and developmentally distinct peritoneal macrophage subsets. Proceedings of the National Academy of Sciences, 107(6), 2568-2573.

Gil-Ortega, M., Stucchi, P., Guzmán-Ruiz, R., Cano, V., Arribas, S., González, M. C., Ruiz-Gayo, M., Fernández-Alfonso, M. S., \& Somoza, B. (2010). Adaptative nitric oxide overproduction in perivascular adipose tissue during early diet-induced obesity. Endocrinology, 151(7), 3299-3306.

Golyshkin, D. V., Falaleeva, T. M., Neporada, K. S., \& Beregova, T. V. (2015). The influence of melanin on the gastric mucosa and hypothalamic-pituitaryadrenocortical axis under acute stress conditions. Physiological Journal, 61(2), 65-72.

Gundamaraju, R., Mulaplli, S. B., \& Ramesh, C. (2012-13). Evaluation of antiobesity activity of Lantana camara var Linn. by progesterone induced obesity on albino mice. International Journal of Pharmacognosy and Phytochemical Research, 4(4), 213-218.

Harford, K. A., Reynolds, C. M., McGillicuddy, F. C., \& Roche, H. M. (2011). Fats, inflammation and insulin resistance: Insights to the role of macrophage and T-cell accumulation in adipose tissue. Proceedings of the Nutrition Society, 70(4), 408-417.

Heilbronn, L. K., \& Campbell, L. V. (2008). Adipose tissue macrophages, low grade inflammation and insulin resistance in human obesity. Current Pharmaceutical Design, 14(12), 1225-1230. 
Hildebrandt, B. A., Racine, S. E., Keel, P. K., Burt, S. A., Neale, M., Boker, S., Sisk, C. L., \& Klump, K. L. (2015). The effects of ovarian hormones and emotional eating on changes in weight preoccupation across the menstrual cycle. International Journal of Eating Disorders, 48(5), 477-486.

Hrabák, A., Derzbach, L., Csuka, I., Bajor, T., \& Körner, A. (2011). Role of nitric oxide (NO) metabolism and inflammatory mediators in childhood obesity. Inflammation Research, 60(11), 1061-1070.

Kaur, G., \& Kulkarni, S. K. (2001). Subchronic studies on modulation of feeding behavior and body weight by neuroteroids in female mice. Methods and Findings in Experimental and Clinical Pharmacology, 23(3), 115-119.

Kern, P. A., Ranganathan, S., Li, C., Wood, L., \& Ranganathan, G. (2001). Adipose tissue tumor necrosis factor and interleukin-6 expression in human obesity and insulin resistance. American Journal of Physiology-Endocrinology and Metabolism, 280(5), 745-751.

Klump, K. L., Keel, P. K., Racine, S. E., Burt, S. A., Neale, M., Sisk, C. L., Boker, $\mathrm{S} ., \& \mathrm{Hu}, \mathrm{J}$. (2013). The interactive effects of estrogen and progesterone on changes in emotional eating across the menstrual cycle. Journal of Abnormal Psychology, 122(1), 131-137.

Lumeng, C. N., Bodzin, J. L., \& Saltiel, A. R. (2007). Obesity induces a phenotypic switch in adipose tissue macrophage polarization. The Journal of Clinical Investigation, 117(1), 175-184.

Marseglia, L., Manti, S., D’Angelo, G., Nicotera, A., Parisi, E., Di Rosa, G., Gitto, E., \& Arrigo, T. (2014). Oxidative stress in obesity: A critical component in human diseases. International Journal of Molecular Sciences, 16(1), 378-400.

Narita, Y., Kitamura, H., Wakita, D., Sumida, K., Masuko, K., Terada, S., Nakano, K., \& Nishimura, T. (2013). The key role of IL-6-arginase cascade for inducing dendritic cell-dependent CD4(+) T cell dysfunction in tumor-bearing mice. The Journal of Immunology, 190(2), 812-820.

Nathan, C. (2008). Epidemic inflammation: Pondering obesity. Molecular Medicine, 14(7-8), 485-492.

Page, S., Chandhoke, V., \& Baranova, A. (2011). Melanin and melanogenesis in adipose tissue: Possible mechanisms for abating oxidative stress and inflammation? Obesity Reviews, 12(5), e21-31.

Pandey, K. B., \& Rizvi, S. I. (2009). Plant polyphenols as dietary antioxidants in human health and disease. Oxidative Medicine and Cellular Longevity, 2(5), 270-278.

Permyakova, N. M., Zheltonozhskaya, T. B., Beregova, T. V., Falalyeyeva, T. M., \& Grishchenko, L. N. (2016). Micellar nanocarriers for anticancer drug melanin. Molecular Crystals and Liquid Crystals, 640(1), 122-133.

Rath, M., Müller, I., Kropf, P., Closs, E. I., \& Munder, M. (2014). Metabolism via arginase or nitric oxide synthase: Two competing arginine pathways in macrophages. Frontiers in Immunology, 5, 532.

Reddy, D. S., \& Kulkarni, S. K. (1998). The role of GABA-A and mitochondrial diazepam-binding inhibitor receptors on the effects of neurosteroids on food intake in mice. Psychopharmacology, 137(4), 391-400.
Sell, H., \& Eckel, J. (2010). Adipose tissue inflammation: Novel insight into the role of macrophages and lymphocytes. Current Opinion in Clinical Nutrition and Metabolic Care, 13(4), 366-370.

Shaw, O. M., Pool, B., Dalbeth, N., \& Harper, J. L. (2014). The effect of diet-induced obesity on the inflammatory phenotype of non-adipose-resident macrophages in an in vivo model of gout. Rheumatology (Oxford), 53(10), 1901-1905.

Sica, A., \& Mantovani, A. (2012). Macrophage plasticity and polarization: in vivo veritas. Journal of Clinical Investigation, 122(3), 787-795.

Skivka, L. M., Fedorchuk, O. G., Rudyk, M. P., Pozur, V. V., Khranovska, N. M., \& Grom, M. Y. (2013). Antineoplastic drug NSC631570 modulates functions of hypoxic macrophages. Cytology and Genetics, 47, 70-82.

Suneetha, D., Divya Teja Banda, S., Ramesh, C., \& Ali, F. (2013). Evaluation of anti-obesity activity of methanolic extract of Sapindus emarginatus by progesterone induced obesity on albino mice. International Journal of Pharmaceutical Sciences Reviews Research, 23(2), 164-169.

Takele, Y., Abebe, T., Weldegebreal, T., Hailu, A., Hailu, W., Hurissa, Z., Ali, J., Diro, E., Sisay, Y., Cloke, T., Modolell, M., Munder, M., Tacchini-Cottier, F., Müller, I., \& Kropf, P. (2013). Arginase activity in the blood of patients with visceral leishmaniasis and HIV infection. PLoS Neglected Tropical Diseases, 7(1), e1977.

Tian, C., Ye, X., Zhang, R., Long, J., Ren, W., Ding, S., Liao, D., Jin, X., Wu, H., Xu, S., \& Ying C. (2013). Green tea polyphenols reduced fat deposits in high fat-fed rats via erk1/2-PPARgamma-adiponectin pathway. PloS One, 8(1), e53796.

Trayhurn, P., Wang, B., \& Wood, I. S. (2008). Hypoxia in adipose tissue: A basis for the dysregulation of tissue function in obesity? British Journal of Nutrition, $100(2), 227-235$.

Vincent, H. K., Vincent, K. R., Bourguignon, C., \& Braith, R. W. (2005). Obesity and postexercise oxidative stress in older women. Medicine and Science in Sports and Exercise, 37(2), 213-219.

Weisberg, S. P., McCann, D., Desai, M., Rosenbaum, M., Leibel, R. L., \& Ferrante, A. W. Jr. (2003). Obesity is associated with macrophage accumulation in adipose tissue. The Journal of Clinical Investigation, 112(12), 1796-1808.

Wood, I. S., de Heredia, F. P., Wang, B., \& Trayhurn, P. (2009). Cellular hypoxia and adipose tissue dysfunction in obesity. Proceedings of the Nutrition Society, 68(4), 370-377.

Wu, D., Ren, Z., Pae, M., Han, S. N., \& Meydani, S. N. (2013). Diet-induced obesity has a differential effect on adipose tissue and macrophage inflammatory responses of young and old mice. Biofactors, 39(3), 326-333.

Zhang, M., Zhou, Z., Wang, J., \& Li, S. (2016). MiR-130b promotes obesity associated adipose tissue inflammation and insulin resistance in diabetes mice through alleviating M2 macrophage polarization via repression of PPAR- $\gamma$. Immunology Letters, 180, 1-8. 